\begin{tabular}{|c|l|}
\hline Title & Effect of chondroitin sulfate and hy al uronic acid on gene expression in a three dimensional culture of chondrocytes \\
\hline Author(s) & Nishimoto, Shohei; Takagi, Mutsumi; Wakitani, Shigey uki; Nihira, Takuya; Y oshida, Toshiomi \\
\hline Citation & $\begin{array}{l}\text { Journal of Bioscience and Bioengineering, 100(1), 123-126 } \\
\text { https://doi.org/10.1263/bb.100.123 }\end{array}$ \\
\hline Issue Date & $2005-07$ \\
\hline Doc URL & http://hdl.handle.net/2115/14716 \\
\hline Type & article (author version) \\
\hline File Information & JBB2005-100-1.pdf \\
\hline
\end{tabular}

Instructions for use 


\section{Effect of Chondroitin Sulfate and Hyaluronic Acid on Gene Expression in a Three-Dimensional Culture of Chondrocytes}

SHOHEI NISHIMOTO, ${ }^{1}$ MUTSUMI TAKAGI, ${ }^{1}{ }^{8}$ SHIGEYUKI WAKITANI, ${ }^{2}$ TAKUYA NIHIRA, ${ }^{1}$ and TOSHIOMI YOSHIDA ${ }^{1}$

International Center for Biotechnology, Osaka University, 2-1 Yamada-oka, Suita, Osaka 565-0871, Japan ${ }^{1}$ and Orthopedic Surgery, Shinshu University School of Medicine, 3-1-1 Asahi, Matsumoto, Nagano 390-8621, Japan² Received 17 January 2005/ Accepted 5 April 2005 NOTES

The effect of glycosaminoglycan addition on a three-dimensional (3D) culture of porcine chondrocyte cells was investigated with a view to use in cartilage regenerative medicine. Chondroitin sulfate $\mathrm{C}$ increased the mRNA expression of type 2 collagen, while chondroitin sulfate A did not. Hyaluronic acid of high molecular weight markedly decreased the mRNA expression of both aggrecan and type 2 collagen, although hyaluronic acid of low molecular weight showed no apparent effect.

[Key words: chondrocyte, chondroitin sulfate, hyaluronic acid, RT-PCR]

*Corresponding author. e-mail: takagi-m@eng.hokudai.ac.jp phone/fax: +81-(0)11-706-6567

${ }^{\S}$ Present address: Division of Biotechnology and Macromolecular Chemistry, Graduate School of Engineering, Hokkaido University, Sapporo 060-8628, 
Japan. 
Although several three-dimensional (3D) cultivation methods of chondrocyte cells were developed with a view to their use in regenerative medicine, sufficient accumulation of extracellular matrices of aggrecan and type 2 collagen has not yet been achieved. While the addition of several cytokines such as transforming growth factor (TGF)- $\beta$ and bone morphogenetic protein (BMP) was shown to increase the production of these extracellular matrices, they are too expensive. On the other hand, the addition of glycosaminoglycans, which are components of aggrecan and not expensive, was investigated (1-3). Several oral supplements of glycosaminoglycans containing hyaluronic acids of high and low molecular weight, which are claimed to effect cartilage repair, are also commercially available. However, there is no report on the influence of glycosaminoglycans such as hyaluronic acids of high and low molecular weight on the gene expression of aggrecan and type 2 collagen.

Recently, a 3D culture method combining a collagen gel and a copolymer mesh of polylactate and polyglucuronic acid (PLGA), which realizes both uniform cell distribution and mechanical strength without shrinkage during culture, was developed (4).

In the present study, the effect of the addition of several glycosaminoglycans on the gene expression of aggrecan and type 2 collagen in chondrocyte cells during 3D culture combining a collagen gel and a PLGA mesh was studied.

Articular cartilage was harvested aseptically from the femoropatellar 
grooves of the knee joints of pigs (4). Chondrocyte cells were cultivated three-dimensionally combining a collagen gel $(0.5 \%, \mathrm{pH} 3$, Kokencellgen I -PCTM; Koken, Tokyo) and PLGA mesh (6 mm $\phi, 0.25 \mathrm{~mm}$ thickness, interval between bundles of fibers; approximately $400 \mu \mathrm{m}$, Vicryl Mesh 910TM; Johnson \& Johnson, Tokyo) (4). The culture medium consisted of MEM (Gibco, NY, USA), 10\% FCS, $2500 \mathrm{U} / 1$ penicillin, $2.5 \mathrm{mg} / 1$ streptomycin, and $50 \mu \mathrm{g} / \mathrm{ml}$ L-ascorbic acid 2-phosphate (Wako Pure Chemicals, Osaka). Several glycosaminoglycans, namely, chondroitin sulfate C sodium salt from shark cartilage (Sigma, St. Louis, MO, USA), chondroitin sulfate A sodium salt from bovine trachea (Sigma), high-molecular-weight hyaluronic acid sodium salt from rooster comb ( $\mathrm{Mw} ; 1,300,000$ - 2,000,000; Sigma), low-molecular-weight hyaluronic acid sodium salt from pig skin ( $\mathrm{Mw}$; 100,000 - 150,000; Seikagaku, Tokyo), heparin sodium salt from pig small intestine (Wako Pure Chemicals), and dermatan sulfate (Sigma), were added to the culture medium. The gelling medium contained $30.5 \mathrm{~g} / \mathrm{M} \mathrm{MEM}, 35.7 \%$ FCS, $8930 \mathrm{U} / /$ penicillin, $8.93 \mathrm{mg} / \mathrm{l}$ streptomycin, and $179 \mu \mathrm{g} / \mathrm{ml} \mathrm{L}$-ascorbic acid 2-phosphate.

The 3D gel culture was hydrolyzed at $37^{\circ} \mathrm{C}$ for $3 \mathrm{~h}$ using $2.5 \mathrm{~g} / \mathrm{l}$ collagenase. Cell concentration was determined by the Trypan Blue method after hydrolysis. Total RNA was extracted from cells after the gel cultures ( $\mathrm{n}=3$ ) using a RNeasy Mini kit (Qiagen, Victoria, Australia). DNase-treated RNA was used to produce cDNA using Omniscript and 
Sensiscript RT kits (Qiagen) and the Gene Amp PCR System 9700 (Applied Biosystems, Foster City, CA, USA). PCR was performed with the cDNA using a HotStar Taq Master Mix kit (Qiagen) and ABI PRISM 7700 (Applied Biosystems) using actin as the standard. The sequences of primers and probes are listed in Table 1. The ratios of the mRNA expression of aggrecan and type 2 collagen to that of actin were calculated.

The collagen-gel culture was rinsed twice with PBS, fixed in $20 \%$ formalin, dehydrated through a graded series of ethanol, infiltrated with isoamyl alcohol, and embedded in paraffin. Sections of $3 \mu \mathrm{m}$ thickness were cut through the center of the gel, rinsed with xylene and ethanol, immersed in hydrogen peroxide (0.3\%) and methanol, and treated with hyaluronidase ( $1 \mathrm{mg} / \mathrm{ml}$, Sigma). Each section was stained with a mouse anti-type 2 collagen antibody (RDI, Flanders, NJ, USA) employing an ImmunoPure Ultra-sensitive ABC mouse IgG staining kit (Pierce, Rockford, IL, USA) and DAB/Metal Concentrate (Pierce).

Three-dimensional cultures were performed for $14 \mathrm{~d}$ employing the culture medium supplemented with several glycosaminoglycans (chondroitin sulfate $\mathrm{C}$, chondroitin sulfate A, hyaluronic acid of high molecular weight, hyaluronic acid of low molecular weight, heparin, and dermatan sulfate), and the degree of expression of aggrecan and type 2 collagen mRNA was determined (Fig. 1). There was almost no change following the addition of heparin and dermatan sulfate (data not shown). The addition of glycosaminoglycans did not influence cell number in the gel 
(Figs. 1 and 2). Hyaluronic acid of high molecular weight markedly suppressed the expressions of aggrecan and type 2 collagen mRNA, while there was no apparent change in the expression with the addition of hyaluronic acid of low molecular weight (Fig. 1).

Chondroitin sulfate A did not affect the expression of type 2 collagen mRNA, while there was a slight increase in aggrecan mRNA expression with the addition of chondroitin sulfate A (10 mg/l) (Fig. 2). On the other hand, chondroitin sulfate $\mathrm{C}(100 \mathrm{mg} / \mathrm{l})$ markedly increased the mRNA expression of type 2 collagen and slightly increased the mRNA expression of aggrecan (Fig. 2). Lower $(10 \mathrm{mg} / \mathrm{D})$ and higher $(1000 \mathrm{mg} / \mathrm{I})$ concentrations of chondroitin sulfate $\mathrm{C}$ had no apparent effect (data not shown).

Sections of cultures with or without the addition of chondroitin sulfate C were stained at 2 weeks with the anti-type 2 collagen antibody (Fig. 3). The three-dimensional culture with the addition of chondroitin sulfate $\mathrm{C}$ gave better staining compared with that without the addition.

The increase in total protein during 4 weeks of $3 \mathrm{D}$ culture was approximately one fifth of the total protein in primary cartilage tissue (data not shown). Thus, improvement of the cultivation conditions may be necessary to obtain appropriate cartilage tissue in vitro for regenerative medicine, while the addition of chondroitin sulfate $\mathrm{C}$ was effective to enhance the gene expression and accumulation of type 2 collagen.

A receptor (annexin 6) for chondroitin sulfate was found on the surface of dermal cancer cells (5), although there is little research on receptors for 
glycosaminoglycans. The results obtained here suggested that chondrocyte cells also have a cell surface receptor for chondroitin sulfate $\mathrm{C}$ and that the binding of chondroitin sulfate $\mathrm{C}$ to this receptor resulted in the increase of the expression of type 2 collagen mRNA. This receptor may not bind chondroitin sulfate A, because there was almost no effect following the addition of chondroitin sulfate A (Fig. 2). The reason for the difference between the two types of hyaluronic acids was not clear.

Consequently, among several glycosaminoglycans; namely, chondroitin sulfates $\mathrm{C}$ and $\mathrm{A}$, hyaluronic acids of high and low molecular weights, heparin, and dermatan sulfate; chondroitin sulfate $\mathrm{C}$ markedly increased the expression level of type 2 collagen mRNA in a 3D culture of chondrocytes, while hyaluronic acid of high molecular weight suppressed both the expression of aggrecan and type 2 collagen mRNAs. Addition of chondroitin sulfate $\mathrm{C}$ might contribute to the accumulation of type 2 collagen during $3 \mathrm{D}$ culture of chondrocyte cells with a view to their use in cartilage regenerative medicine, while the influence of the addition of chondroitin sulfate $\mathrm{C}$ on the accumulation of type 2 collagen should be determined.

\section{REFERENCES}

1. van Susante, J.L.C., Pieper, J., Buma, P., van Kuppevelt, T.H., van 
Beuningen, H., van Der Kraan, P.M., Veerkamp, J.H., van den Berg, W.B., and Veth, R.P.H.: Likage of chondroitin-sulfate to type I collagen scaffolds stimulates the bioactivity of seeded chondrocytes in vitro. Biomaterials, 22 , 2359-2369 (2001).

2. Louis, L., John, W., Robert, K., and Tarek, A.: In vivo chondroprotection and metabolic synergy of glucosamine and chondroitin sulfate. Clin. Orthop. Relat. Res, 381, 229-240 (2000).

3. Kawasaki, K., Ochi, M., Uchio, Y., Adachi, N., and Matsusaki, M.: Hyaluronic acid enhanced proliferation and chondroitin sulfate synthesis in collagen gels. J. Cell. Physiol., 179, 142-148 (1999).

4. Takagi, M., Fukui, Y., Wakitani, S., and Yoshida, T.: Effect of PLGA mesh on a three-dimensional culture of chondrocytes. J. Biosci. Bioeng., 98, 477-481 (2004).

5. Takagi, H., Asano, Y., Yamakawa, N., Matsumoto, I., and Kimata, K.: Annexin 6 is a putative cell surface receptor for chondroitin sulfate chains. J. Cell Sci., 115, 3309-3318 (2002). 
TABLE 1. Sequences used in PCR

\begin{tabular}{|c|c|}
\hline Gene & Sequences \\
\hline $\begin{array}{l}\text { Porcine Aggrecan } \\
(\text { AF201722) }\end{array}$ & $\begin{array}{l}\text { Sense: } \\
\text { 5'-TGCAGGTGACCATGGCC-3' } \\
\text { Anticans: }\end{array}$ \\
\hline & Probe: $\quad$ 5'-CCCTGGGCAGCCACGACTTCC-3' \\
\hline $\begin{array}{l}\text { Porcine Type } 2 \\
\text { collagen } \alpha 1\end{array}$ & $\begin{array}{l}\text { Sense: } \\
\text { 5'-CCATCTGGCTTCCAGGGAC-3' } \\
\text { Antisense: 5'-CCACGAGCCAGGAGCT-3' }\end{array}$ \\
\hline (AF201724) & Probe: 5'-ACCAGGAACGCCCTGATCACCTGG-3' \\
\hline Porcine Actin & Sense: $\quad 5^{\prime}$-TGCAGGTGACCATGGCC-3' \\
\hline （SSU07786） & $\begin{array}{l}\text { Antisense: 5'-CGGTAATGGAACACAACCCCT-3' } \\
\text { Probe: }\end{array}$ \\
\hline
\end{tabular}


FIG. 1. Effect of hyaluronic acids on the expression of aggrecan and type 2 collagen mRNA in a three-dimensional culture of porcine chondrocyte cells. (A) Hyaluronic acid $(\mathrm{H})$, hyaluronic acid of high molecular weight; (B) hyaluronic acid (L), hyaluronic acid of low molecular weight.

FIG. 2. Effect of chondroitin sulfates on the expression of aggrecan and type 2 collagen mRNA in a three-dimensional culture of porcine chondrocyte cells. (A) Chondroitin sulfate C; (B) chondroitin sulfate A.

FIG. 3. Effect of chondroitin sulfate $\mathrm{C}$ on type 2 collagen accumulation in 3D culture. The sections of 3D cultures with (A) or without (B) the addition of chondroitin sulfate $\mathrm{C}$ were stained with the anti-type 2 collagen antibody. 

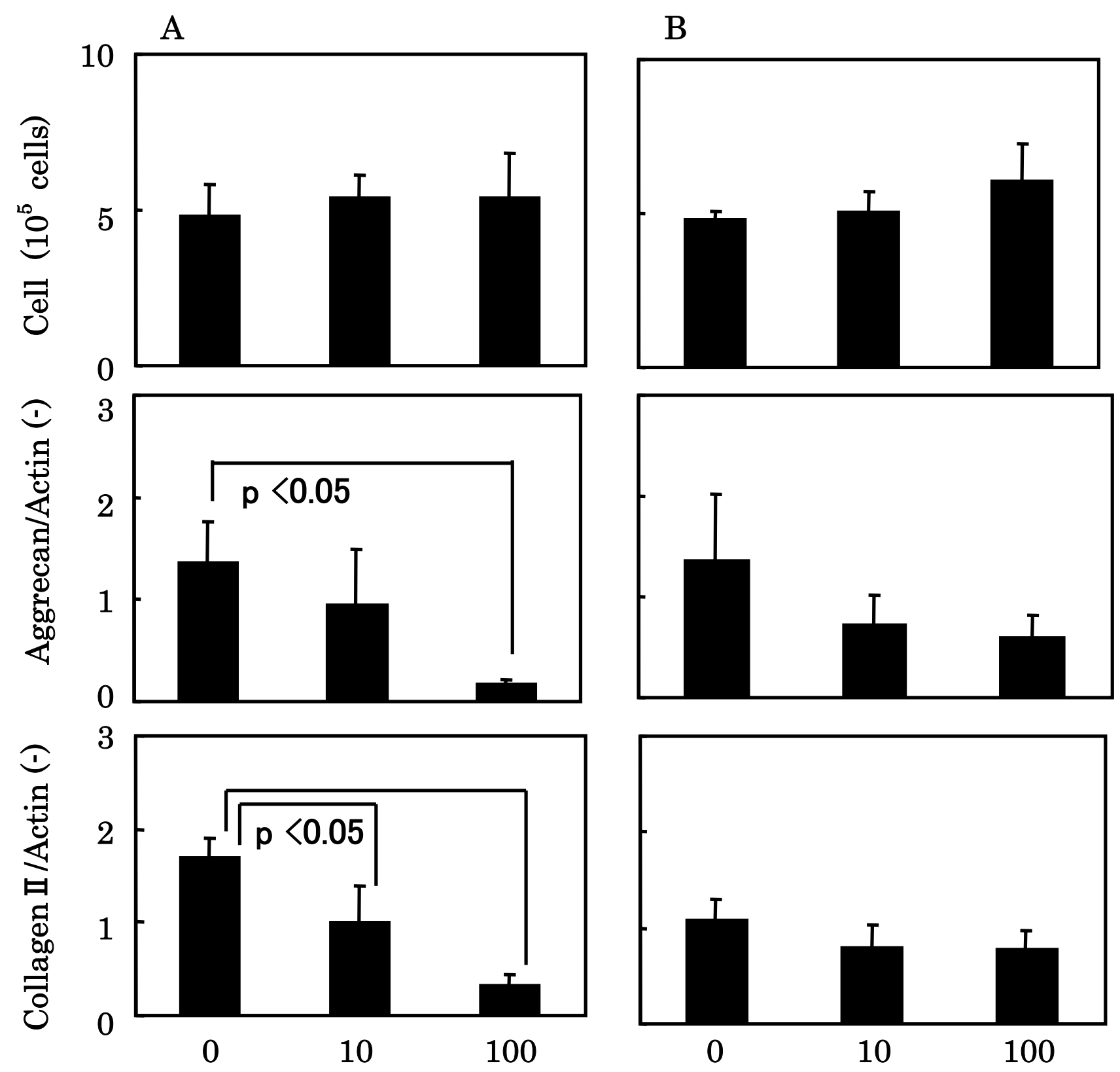

Hyaluronic acid (H) concn. (mg/D) Hyaluronic acid (L) concn. (mg/D) 

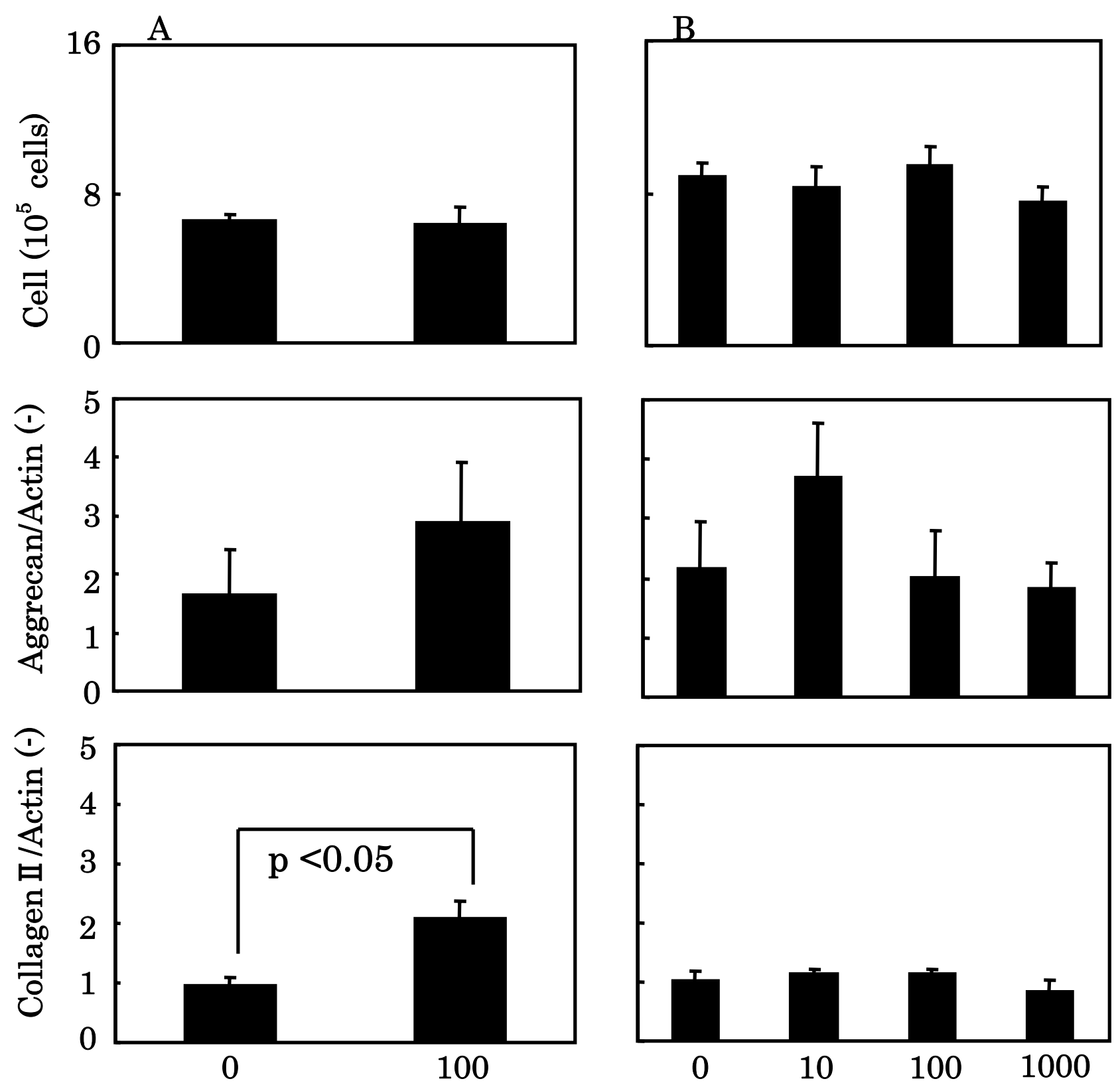

Chondroitin sulfate C concn. (mg/l) Chondroitin sulfate A concn. (mg/l) 
A

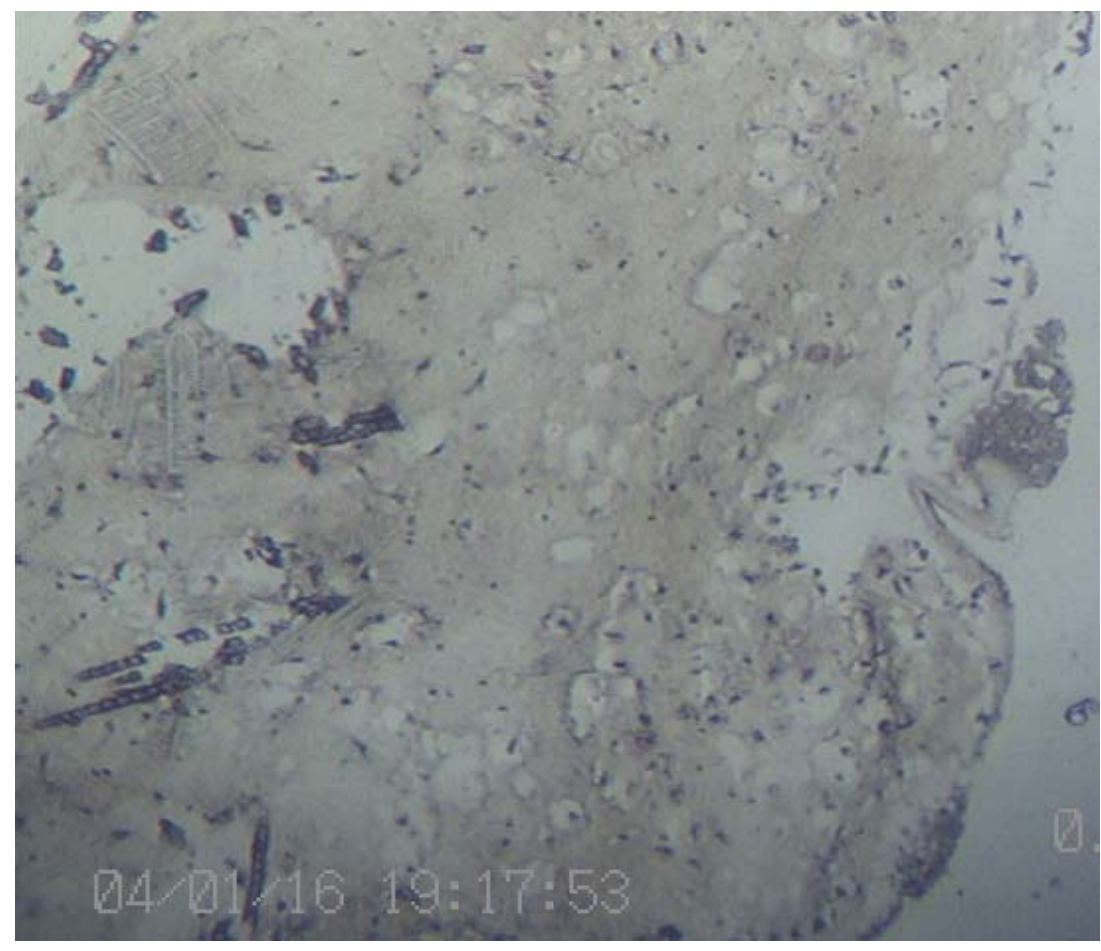

B

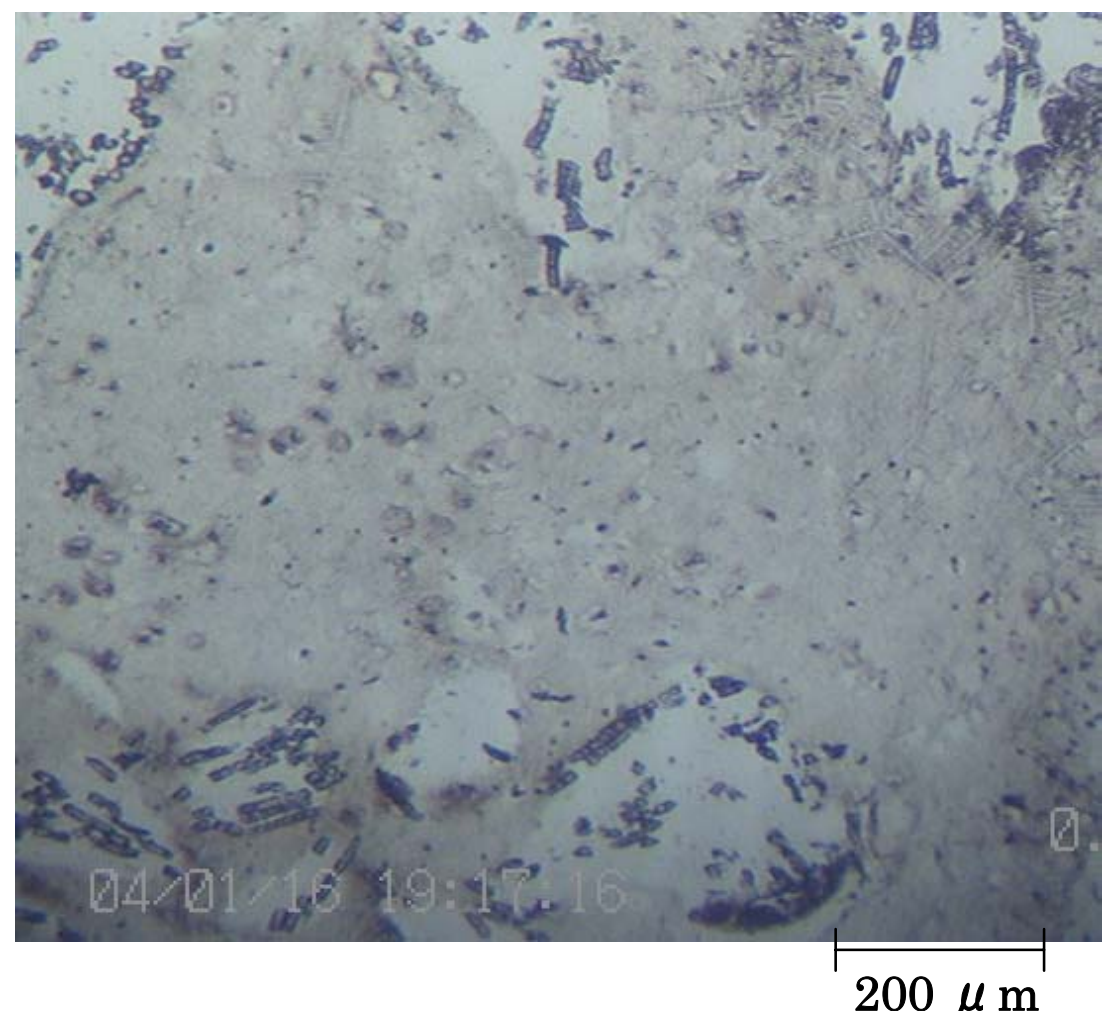

